\title{
Sharing Health Risk and Income Risk within Households: Evidence from J apanese Data
}

\author{
Atsushi Yoshida * \\ University of Tsukuba \\ 1-1-1, Ten-noudai, Tsukuba, Ibaraki 305-8573, Japan \\ Youg-Sook Kim \\ University of Tsukuba \\ 1-1-1, Ten-noudai, Tsukuba, Ibaraki 305-8573, Japan
}

\begin{abstract}
A bstract
We examine the question of which household members should consume medical services, and in what quantities, by using J apanese household-level data. We employ two key concepts, health risk and income risk, and investigate whether family heads or dependents bear these risks. Health risk is the risk that a household member falls ill, while income risk is the risk that future household income decreases. We find that both heads and dependents make fewer visits to doctors as household size increases. We also find that only dependents visited doctors less frequently following the reform of the public health insurance system, which raised the co-payment rate of family heads from $10 \%$ to $20 \%$. These findings imply that heads and dependents share health risk but dependents bear income risk.

K eywords: co-payment; health risk; income risk; public health insurance

J EL classification: D13, I10, I18
\end{abstract}

*CORRESPONDENCE: Atsushi Yoshida, Institute of Policy and Planning Sciences, University of T sukuba, 1-1-1, Ten-noudai, T sukuba, Ibaraki 305-8573, J apan. TEL\&FAX: +81-29-853-5095. Email: ayoshida@sk.tsukuba.ac.jp 


\section{Introduction}

A primary concern for a household is the health of its members. However, since household income is limited, the issue of which household members should consume medical services, and in what quantities, is a serious one. In this paper, we examine this issue by using Japanese household-level data.

All Japanese citizens are insured by the public health insurance system. In particular, employees (hereafter referred to as heads) of large companies and their dependents are insured by a health insurance association managed by the company. In addition to premiums, the insured must pay some proportion of their bills for medical services, termed the co-payment, over the counter at clinics or hospitals. Before the reforms introduced in September 1997, the co-payment rate was set at $10 \%$ for heads and $30 \%$ for dependents. The reform raised the co-payment rate for heads to $20 \%$, while the rate for dependents remained unchanged.

Table 1 shows who consumed medical services and in what quantities before and after the reform. First, both heads and dependents made fewer visits to doctors as the number of dependents increased, both before and after the reform. Second, after the reform dependents reduced their number of doctor visits by much more than did heads (see also figures 1 and 2). The decline in the number of doctor visits by heads is negligible. We attempt to explain these facts by making theoretical assumptions about the behavior of household members.

The first fact implies that both heads and dependents act to reduce the risk of illness among other family members by reducing their consumption of health services equally. In other words, households seem to pool the total risk of illness among their members, hereafter referred to as health risk, by sharing health care expenditure among household members. If a household is 
formed solely so that household members can reduce living costs by sharing a house, its contents and the car and the head is egoistic, we cannot explain the first fact. Since health services are private services, any reduction in these services reduces individual health levels. When the head is benevolent and altruistic towards dependents, as Becker (1974) assumed, both facts can be explained. Becker's model is sometimes referred to as a unitary model in which the head, whether egoistic or altruistic, decides shares of expenditure among household members and the household is regarded as an economic unit in itself. Even if only heads earn income, the model may be restrictive and unrealistic because housekeeping by spouses contributes to the work of heads.

On the other hand, models in which households decide how to share expenditure between members are referred to as collective models. A cooperative bargaining model is one form of collective model. Manser and Brown (1980) and McElroy and Horney (1981) are seminal papers in the context of the cooperative approach. Pezzin and Schone (1999) examined how intergenerational households are formed when informal caregiving to an elderly parent and labor-force participation by daughters are jointly determined. Chiappori (1988) and Bourguignon and Chiappori (1992) established a rigorous theoretical and empirical framework for collective models to avoid having to specify a particular bargaining set-up.

In our paper, the first and second facts can be explained by assuming that dependents have bargaining power over the head to some extent and that they act egoistically. An increase in the number of dependents enhances their bargaining power, which makes the head reduce his or her visits to the doctor. This explains the first fact, which relates to pooling health risk. If dependents decide their consumption levels independently and in their own 
interests, the change in the head's co-payment rate would not affect visits to the doctor by dependents provided household income remains unchanged. If a head is reluctant to visit a doctor because of the co-payment increase, the head may fall ill, which may reduce future household income. Hence, we refer hereafter to income risk. When the income risk is high, the bargaining power of the head is high, in which case, dependents would share the risk even if they were egoistic. This may explain the second fact. Dercon and Krishnan (2000) adopted a collective approach to explain the intra-household allocation of nutritional levels using the idea of risk sharing.

Let us summarize the above discussion briefly. There are two axes, one representing the decision-making process, unitary or collective, the other representing behavioral motives, egoistic or altruistic. The unitary-egoistic case cannot explain the two facts illustrated by table 1 and apparent in the figures. The unitary-altruistic and collective-altruistic cases can explain these facts. The predominant idea, altruism, can explain all possible types of behavior by household members, however it fails to provide specific explanations for these facts. Thus, we choose the collective-egoistic approach to explain the facts using two key concepts, health risk and income risk. The purpose of this paper is to examine whether the hypotheses of health risk and income risk sharing are supported by the data by using statistical models that control for household/individual characteristics.

We specify individual visits to the doctor (hereafter, doctor visits) by the head and dependents as hurdle negative-binomial models (see chapter 4 of Cameron and Trivedi, 1998, and Pohlmeier and Ulrich, 1996). This model can deal with data generated from two potentially different decision processes. In the Japanese public health insurance system, a doctor may be able to influence the number of doctor visits. Hence, specifying two decision 
processes, the decision of the insured and the combined decision of the insured and a doctor, is reasonable. The former is modeled in the hurdle part by using the logit model and the latter is modeled in the positive-visits part by the truncated negative-binomial model (see Yoshida and Takagi, 2002, for an application to Japanese data).

The paper is organized as follows. In section 2, we describe characteristics of the data used in the empirical analysis. In section 3, we present the empirical models. In section 4, we interpret our estimation results from the viewpoints of health risk and income risk sharing. Section 5 concludes the paper.

\section{The Data}

We use data on bills (reseputo in Japanese) from medical institutions, hospitals and clinics, to a health insurance association. When an insured person visits a medical clinic at least once in a month, the clinic sends a reseputo to the health insurance association for the medical cost incurred in that month after the over-the-counter co-payment has been made. If a patient visits two different clinics in a month, the association receives two reseputos for that patient. We use information from reseputos for outpatients.

The reseputo data include the monthly number of doctor visits and the co-payment made over the counter by the insured. The data also include a household-identification number and the head's income on which the insurance fee is levied, as well as socio-economic characteristics such as age, gender, and household composition (covering spouse, children, grandparents and relatives). Thus, we have information on who is in a particular insured household and how many times a household member visits a doctor in a month. 
Since we are concerned with intra-household resource allocation, we are interested in the structure of households, which relates to who is the main income earner and who are the dependents. There are three types of household. The first is one in which there are two parents, a husband and wife, with the husband being the head in most cases, and dependents, namely a spouse, children, grandparents or relatives. The second type is one in which both parents are heads, that is, full-time workers, and there are dependents. The third type is the household in which there is only one parent, with he or she being the head, and there are dependents. Single-person households are excluded from our study. In our data, we cannot distinguish between the second and third household types. In both, there is no dependent spouse. However, intra-household resource allocation is different in the two types because husband and wife have similar bargaining power in the second household type. Hence, for this type of household, income risk is not as important as it is for the first and third household types. Thus, for estimation, initially we use the data on all three household types and then use the data on only the first household type (hereafter, type-1 households).

The reform was introduced in September 1997. To examine the effects of the reform, we aggregate monthly-based reseputo data to yearly-based data, covering the pre-reform period from September 1996 to August 1997 and the post-reform period from September 1997 to August 1998. We aggregate at both the individual and household levels.

Using data on all three household types, table 1 shows the average percapita number of doctor visits in both the pre-reform and post-reform periods by household status, head or dependent, and by the number of dependents. In the table, ' 0 included' or ' 0 excluded' indicates whether persons not visiting a doctor are included or excluded. The number of insured persons in our 
data set is 17,026 , of which 5,161 are heads and 11,865 are dependents. The average household has one head and two dependents.

The data confirm the two facts reported in the introduction. First, both heads and dependents reduce doctor visits as the number of dependents increases, in both pre- and post-reform periods. Second, the dependents reduced their doctor visits by more than did heads following the reform (see table 1 and figures 1 and 2). The decline in doctor visits among heads was negligible.

In the 0-excluded pre-reform case, the number of doctor visits by heads fell from 13.71, with one dependent, to 9.30, with more than three dependents, while those of dependents fell from 17.30 to 13.00. Similar falls were experienced following the reform. Since heads with fewer dependents tend to be younger and healthier, their number of doctor visits is expected to be lower than the number of visits by heads with many dependents. However, table 1 contradicts this expectation. This implies that the head shares the health risk of dependents. This is perhaps supported by the fact that the number of doctor visits by dependents increased from 11.39, with three dependents, to 13.00 , with more than three dependents, in the pre-reform period. The corresponding change for the post-reform period is from 10.57 to 12.05. These increases are understandable because large households tend to include infants or elderly people as dependents who need intensive health care, and whose risks are shared by the head.

Figures 1 and 2 illustrate probability densities for the number of doctor visits by heads and dependents, respectively. The pre-reform density for heads does not differ from the post-reform density. However, the probability density for dependents changes between these periods: the probability of a large number of doctor visits falls, and that of a smaller number rises. This 
means that the dependents who visit a doctor regularly reduce the frequency of their visits. Among all 0 -excluded cases in table 1, heads reduced the number of doctor visits by 0.24 following the reform, while dependents reduced their visits by 0.75 . In particular, in households with more than three dependents, dependents reduced their visits by 0.95 , while heads increased their visits by 0.02 . These facts suggest that dependents reduce their medical consumption so that heads can maintain their levels of medical expenditure following increased co-payment rates for heads to avoid the income risk associated with illness among heads.

\section{Empirical Models}

Since the dependent variable, the number of doctor visits per year, takes non-negative integer values, we use a count data model, the hurdle negativebinomial (HNB) model. The model can be interpreted as a two-part model. While the first part models the probability that the zero hurdle is crossed, the second part models the positive outcome. We use the logit model for the hurdle part. The probability that the $i$ th individual visits a doctor is modeled as

$$
\operatorname{Pr}\left[Y_{i}=1\right]=\frac{\exp \left(X_{1 i} \beta_{1}\right)}{1+\exp \left(X_{1 i} \beta_{1}\right)}
$$

where $X_{1 i}$ represents the characteristics of the $i$ th household and/or the individual socio-economic characteristics of dependents.

The probability function of the negative-binomial model is used to model the positive outcome. Note that two types of negative binomial (NB) model are used in practice, NB1 and NB2. The difference between them is the functional form for the variance: in NB1, the variance is a linear function of the mean, while in NB2, it is a quadratic function. We use the NB2 model. 
The density function for the positive outcome is

$$
f(y \mid \mu, \alpha)=\frac{\Gamma\left(\alpha^{-1}+y\right)}{\Gamma\left(\alpha^{-1}\right) \Gamma(y+1)}(\alpha \mu)^{y}(1+\alpha \mu)^{-\left(y+\alpha^{-1}\right)}
$$

where $\mu$ and $\alpha$ are the mean and the dispersion parameters of the distribution, respectively. Then, the positive outcome is modeled as

$$
\operatorname{Pr}\left[Y_{i}=y \mid Y_{i}>0\right]=\frac{f\left(y \mid \mu_{i}, \alpha\right)}{1-f\left(0 \mid \mu_{i}, \alpha\right)}
$$

The mean function, $\mu_{i}$, is modeled as $\exp \left(X_{2 i} \beta_{2}\right)$ where $X_{2 i}$ represents the characteristics of the $i$ th household and/or the individual socio-economic characteristics of dependents. The likelihood function is decomposed into two parts, as follows:

$$
\mathcal{L}_{1}\left(\beta_{1}\right)=\Pi_{\left(i: Y_{\mathrm{i}}=0\right)} \operatorname{Pr}\left[Y_{i}=0\right] \Pi_{\left(i: Y_{\mathrm{i}}>0\right)}\left(1-\operatorname{Pr}\left[Y_{I}=0\right]\right),
$$

and

$$
\mathcal{L}_{2}\left(\alpha, \beta_{2}\right)=\Pi_{\left(i: Y_{\mathrm{i}}>0\right)} \operatorname{Pr}\left[Y_{i}=y \mid Y_{i}>0\right]
$$

where estimates of $\beta_{1}, \alpha$ and $\beta_{2}$ are obtained by maximizing $\mathcal{L}_{1}\left(\beta_{1}\right)$ and $\mathcal{L}_{2}\left(\alpha, \beta_{2}\right)$ separately.

As already discussed, the number of doctor visits of the head (dependent) is affected by the number of dependents because health risk is shared. Following the reform, heads may not have changed their number of doctor visits but dependents may have because they share income risk. The sharing of income risk seems to take place primarily among dependents. We estimate the numbers of visits by heads and dependents to examine who shares income risk.

A list of the variables and their descriptive statistics for heads and dependents is shown in table 2. The explanatory variables are classified into two categories, individual-specific and household-specific explanatory variables. 
Since households have only one head in our data set, the characteristics of heads are categorized as household-specific explanatory variables, and visits by heads depend only on these variables. Dependents' visits are explained by the variables in both categories. The base case for dependents is that in which gender is female, and household status corresponds to grandparents or other relatives.

The co-payment rate is calculated by dividing over-the-counter fees by the total medical fee according to the reseputo. Note that the co-payment rate is omitted in the hurdle part of the model because only its nominal rate, $10 \%$ ( $20 \%$ following the reform) or $30 \%$, is observed by the insured beforehand. Then, the co-payment rate is indistinguishable from the constant term of the model. In general, the actual rate differs from the nominal rate because financial support is incorporated. Hence, the co-payment rate is identified in the positive-outcome part of the model.

To examine the effects of the reform, we include among the explanatory variables post-reform variables, which are zero in the pre-reform period. We constructed a post-reform dummy that is unity in the post-reform period and zero otherwise. Then, post-reform variables were constructed by multiplying the explanatory variables by this dummy. The coefficients of the post-reform variables represent the effects of the variables following the reform. If the coefficients are statistically insignificant, the effects of the variables are no different following the reform.

\section{Estimation R esults}

\subsection{Results Based on Data from All Three Household Types}

A. The Hurdle Part 
We use data on all household types in this subsection. Tables 3 and 4 report the estimation results of heads and dependents, respectively.

First, the hurdle-part estimation results for heads indicate whether heads or dependents reluctant to visit doctors in order to share health risk. Whether heads share health risk is indicated by the coefficients of no. of dependents. This coefficient is significantly negative, which implies that heads share health risk in their decisions to visit a doctor.

We have already explained that, given the properties of the data set, risk-sharing behavior of type-1 households is likely to different from that of other-types households. In a type-1 household, insured-spouse dummy takes a value of unity, but otherwise is zero. The estimate of the coefficient is not significant, which implies that there is no difference between heads of type-1 and other-types households in relation to sharing health risk.

Age of dependents is an important factor for health risk because infants and the elderly often fall ill. The coefficient of no. of dependents over 69 is significantly negative, while that of no. of dependents under 9 is significantly positive. Since medical expenditure for infants is supported by local governments and because childhood illnesses are not generally serious or costly, this expenditure may not affect the number of doctor visits by heads. However, since illness among the elderly is often chronic and costly, the head who shares health risk must consider this when deciding whether to visit a doctor.

We also used sum of dependents' doctor visits and no. of dependents visiting a doctor as explanatory variables to control for household-specific effects such as peer effects of a household or accessibility to clinics. All of the members of a household tend to consume more medical services given household-level income than did other households. This is because households have similar propensities to consume services as a result of learning 
about the costs and the benefits of these services from each other. These effects are regarded as peer effects. We have no information on accessibility to clinics among households in our data, but access cost is likely to affect a household's number of doctor visits. Thus, the signs of the coefficients of these variables are expected to be positive.

The coefficient of age of head is significantly positive and that of monthly income is significantly negative. The head tends to visit the doctor because he or she is older. The head's income may be a proxy for the opportunity cost of visiting a doctor. Alternatively, the result shows that the rich are healthier.

Second, we examine the hurdle part for dependents in table 4. Among household-specific variables, the coefficients of no. of dependents over 69, no. of children and no. of dependents are significantly negative, which suggest that dependents are reluctant to visit a doctor if there is an elderly dependent person, many children or many dependents in the household. This implies that dependents, as well as heads, also share health risk.

The coefficients of age of head and monthly income are significantly positive. Income affects visits by dependents differently to visits by heads. This may reflect the lower opportunity cost of dependents. The coefficients of head's visits and no. of dependents visiting a doctor, which represent household-specific effects, are insignificantly positive and significantly positive, respectively.

Next, we examine how individual characteristics affect decisions to visit the doctor. The coefficients of age, gender dummy (male=1), spouse dummy and child dummy are all significantly negative. Adults and females are reluctant to visit a doctor. Spouses and children visit doctors less than do grandparents or other relatives. Only over-69 dummy is significantly posi- 
tive.

Note that none of the post-reform variables for heads or dependents is significant. This implies that neither heads nor dependents behaved differently following the reform in relation to visiting a doctor.

\section{B. The Positive-Visits Part}

Here, we examine the positive-visits part of the model.

Tables 3 and 4 report the estimation results for heads and dependents, respectively. In table 3, for the pre-reform period, almost half of the explanatory variables for the doctor visits by heads are significant. The variables that are significant at the $5 \%$ level are the constant term, age of head, sum of dependents' visits, no. of dependents and co-payment rate. However, for the post-reform period, only co-payment rate is significant. Older heads visit doctors more frequently. The more often dependents visit a doctor, the more heads visit. This represents household-specific effects such as peer effects or the accessibility to clinics. Monthly income is significantly negative at the $10 \%$ level, as in the hurdle part. Common results to both hurdle and positive-visits parts of the model suggest that heads with higher incomes are healthy, because they spend more on preventative health goods/services or because their opportunity costs are high.

The negative co-payment rate indicates that heads whose medical expenditure is financially supported visit a doctor more frequently. Although the coefficient of the post-reform co-payment rate is positive, the overall effect, $-0.053+0.043$, is negative. Doctor visits by heads are less elastic with respect to co-payment rate than before the reform. The effects of the copayment rate on heads' visits changes from $-0.53(=-0.053 \times 10 \%)$ to -0.20 $(=(-0.053+0.043) \times 20 \%)$. Hence, the change in the co-payment rate did not 
have a negative effect on the doctor visits by heads in general.

Since no. of dependents is significant, heads share health risk with dependents when deciding how many times to visit a doctor. This is the same as the head's decision about whether he or she should visit a doctor, which is obtained from the hurdle-part of the model. These findings suggest that dependents have some bargaining power over heads' visits.

The estimates of the positive-visits part of the model for dependents are reported in table 4. For the household-specific pre-reform variables, the coefficients of no. of children and no. of dependents, which are related to health risk sharing behavior, are significantly negative. The no. of dependents over 69 is significant at almost the $10 \%$ significance level. These results imply that dependents share health risk among themselves. Monthly income is also significantly negative. This negative sign, together with its positive sign in the hurdle part, suggests that the dependents of a wealthy household are not reluctant to visit a doctor immediately on feeling ill, and thus they soon recover. The coefficients of the household-specific effects variables, head's visit and no. of dependents visiting a doctor, are significantly positive, as expected.

For individual-specific pre-reform variables, age, spouse dummy, child dummy and co-payment rate are significantly negative, while gender dummy (male $=1$ ) is significantly positive. The over-69 dummy is not significant. The coefficients of age and over-69 dummy imply that doctor visits of dependents decrease slowly with age. Males tend to visit doctors more than females, and both spouses and children visit less than grandparents or other relatives. Note that since females and grandparents or other relatives are the base case for estimation, the constant term may also reflect the effects of aging. 
For the post-reform variables, the significant variables are the constant term, no. of dependents visiting a doctor and co-payment rate, which are all negative. Of the individual-specific variables spouse dummy is negative at almost the $10 \%$ significance level. The negative signs of the constant and spouse dummy suggest that dependents share income risk.

\section{Tests}

We also conducted likelihood ratio (LR) tests for the HNB models for both heads and dependents, with the null hypothesis being that the coefficients of the post-reform variables are jointly zero. The results are reported in table 7. The null is rejected in the dependents model but not in the heads model.

The issue of whether heads or dependents share income risk, as suggested by the coefficients of the constant term (for both heads and dependents), spouse dummy and child dummy (for dependents only) for the post-reform variables, should be examined more closely. We have already found that the coefficient of the constant term for heads in the positive-visits part of the model is not significant. By contrast, the coefficients of the constant term, spouse dummy and child dummy for dependents are significantly negative. However, these findings are not sufficient to suggest that only dependents share income risk or that dependents at least share income risk more than do heads. To make this case, we must consider the standard errors of the estimates.

Changes in the number of doctor visits made by heads due to income risk are represented by the estimates of the constant term. For dependents' visits, spouses' changes are represented by the estimates of the constant term + spouse dummy. Changes for children's visits are represented by the constant term + child dummy. Changes for grandparents or other relatives are 
represented by the constant term + over-69 dummy. We advance three null hypotheses. We tested whether changes for heads and dependents are significantly different. The test statistics, $Z$, are calculated as follows:

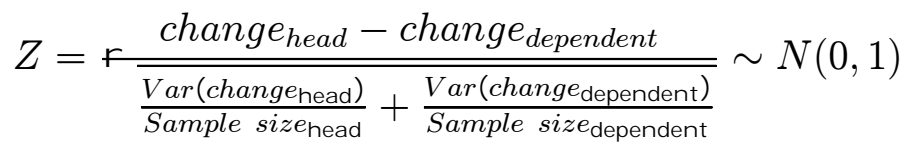

The results are reported in table 7 . The null hypothesis that changes in doctor visits for heads and dependents are no different is rejected for heads against spouses and for heads against children but not for heads against grandparents or other relatives (abbreviated over-69 in the table). Since most of those over-69 are grandparents, only dependents other than grandparents share income risk, or dependents at least share income risk more than do heads.

\subsection{Type-1 Household Data}

We use type-1 household data for estimation. These households have two parents, a husband and wife, with the husband being the head in most cases, and dependents, namely a spouse, children, and grandparents or relatives. The results are almost the same as those of the model using data on all household types, and the models have larger pseudo R-squared values. Note that insured-spouse dummy for the household-specific variables is omitted because all households of this type have insured spouses.

Tables 5 and 6 show the estimation results for heads and dependents.

Table 5 indicates that heads share health risk. The main difference between the results for heads from type- 1 households and those for heads from data on all household types is that monthly income is not significant in the former but is significantly negative in the latter.

Table 6 clearly shows that dependents share health risk and income risk. 
Since the estimates of the pre-reform variables are the same as those obtained from the data on all household types, we focus on the post-reform variables. In the hurdle part, the constant term is significantly negative, which implies that dependents share income risk as well as health risk when deciding whether to visit a doctor. Although spouse dummy is significantly positive, the total effect, which is given by constant term + spouse dummy, remains negative, so the positive sign does not change the results. In the positivevisits part of the model, the main difference between the type- 1 results and the all-types results is that the constant term is insignificant, child dummy is significant, and the spouse dummy is significant at almost the $10 \%$ level. This implies that dependents share income risk.

Table 7 also shows that the same results are obtained when using type-1 data or all-types data. The LR-test results suggest that heads did not change their behavior but that dependents did. The Z-test results also suggest that spouses and children share income risk.

\section{Conclusion}

In this paper, we examined the question of which household members should consume medical services, and in what quantities, by using Japanese householdlevel data. We used two key concepts, health risk and income risk, and investigated whether heads or dependents share these risks. Health risk is the risk that a household member falls ill, while the income risk is the risk that future household income decreases. We found that both family heads and dependents visit doctors less often as household size increases, and that only dependents visited a doctor less frequently following the reform of the public health insurance system, which raised the co-payment rate for heads from $10 \%$ to $20 \%$. These findings imply that both heads and dependents share 
health risk but only dependents share the income risk.

These differences in risk sharing between heads and dependents can be explained by collective models. Dependents have some bargaining power over heads since they manage housework and support employed heads. Hence, heads share health risk to maintain efficiency at work. However, reduced doctor visits by heads due to the increased co-payment rate may reduce future household income. Thus, dependents reduced their doctor visits so that the number of doctor visits by heads could remain unchanged following the reform.

Although most of the findings of this paper can be explained by egoistic motives in a collective framework, the exception is the finding that the elderly share neither health risk nor income risk. This may be because the elderly are wealthy. However, since wealthy elderly people are not classified as dependents by the public health insurance system, this cannot be the explanation. Therefore, what is the explanation? The altruism of family heads or younger dependents may provide an explanation, but this remains to be examined empirically.

\section{R eferences}

[1] Becker, G.(1974) A Theory of Social Interaction, J ournal of Political E conomy, 82, 1063-93.

[2] Bourguignon, F. and P. A. Chiappori(1992) Collective Models of Household Behavior: An Introduction, European E conomic Review, 36, 355364.

[3] Cameron, A. C. and P. K. Trivedi(1998) Regression analysis of count data, Cambridge University Press: New York. 
[4] Chiappori, P. A.(1988) Rational Household Labor Supply, Econometrica, ,bf 56, 63-90.

[5] Dercon, S. and P. Krishnan(2000) In Sickness and in Health: Risk Sharing within Households in Rural Ethiopia, J ournal of P olitical E conomy, 108, No.4, 688-727.

[6] Manser, M. and M. Brown(1980) Marriage and Household DecisionMaking: A Bargaining Analysis, International Economic Review, 21, $31-44$.

[7] McElroy, M. B. and M. J. Horney(1981) Nash-Bargained Household Decisions: Toward a Generalization of the Theory of Demand, International Economic Review, 22, No.2, 333-49.

[8] Pezzin, L. E. and B. S. Schone(1999) Intergenerational Household Formation, Female Labor Supply and Informal Caregiving: A Bargaining Approach, J ournal of Human Resources, 34, No.3, 475-503.

[9] Pohlmeier, W. and V. Ulrich(1995) An Econometric Model of the TwoPart Decision-Making Process in the Demand for Health Care, J ournal of Human Resources, 30, No.2, 339-61.

[10] Yoshida, A. and S. Takagi(2002) Effects of The Reform of the Social Medical Insurance System in Japan, The J apanese Economic Review, 53, No. 3, 444-65. 
Table 1: Changes in per capita number of doctor visits by the number of dependants

\begin{tabular}{|c|c|c|c|c|c|c|c|c|c|c|c|c|}
\hline \multirow{3}{*}{$\begin{array}{l}\text { No. } \\
\text { dependants }\end{array}$} & \multicolumn{6}{|c|}{ Pre-reform } & \multicolumn{6}{|c|}{ Post-reform } \\
\hline & \multicolumn{2}{|c|}{ Head } & \multicolumn{2}{|c|}{ Dependant } & \multicolumn{2}{|c|}{ Total } & \multicolumn{2}{|c|}{ Head } & \multicolumn{2}{|c|}{ Dependant } & \multicolumn{2}{|c|}{ Total } \\
\hline & 0 incl & 0 excl & 0 incl & 0 excl & 0 incl & 0 excl & 0 incl & 0 excl & 0 incl & $0 \mathrm{excl}$ & 0 incl & 0 excl \\
\hline \multicolumn{13}{|l|}{1} \\
\hline No. obs. & 1497 & 1138 & 1497 & 1238 & 2994 & 2376 & 1497 & 1144 & 1497 & 1238 & 2994 & 2382 \\
\hline No. visits & 10.43 & 13.71 & 14.31 & 17.30 & 12.37 & 15.58 & 10.27 & 13.44 & 14.18 & 17.15 & 12.22 & 15.37 \\
\hline \multicolumn{13}{|l|}{2} \\
\hline No. obs. & 1398 & 1099 & 2796 & 2315 & 4194 & 3414 & 1398 & 1075 & 2796 & 2291 & 4194 & 3366 \\
\hline No. visits & 9.15 & 11.64 & 11.71 & 14.15 & 10.86 & 13.34 & 8.84 & 11.50 & 10.95 & 13.37 & 10.25 & 12.77 \\
\hline \multicolumn{13}{|l|}{3} \\
\hline No. obs. & 1612 & 1208 & 4836 & 4035 & 6448 & 5243 & 1612 & 1194 & 4836 & 3991 & 6448 & 5185 \\
\hline No. visits & 7.58 & 10.12 & 9.50 & 11.39 & 9.02 & 11.09 & 7.15 & 9.66 & 8.72 & 10.57 & 8.33 & 10.36 \\
\hline \multicolumn{13}{|l|}{ more than 3} \\
\hline No. obs. & 654 & 510 & 2736 & 2306 & 3390 & 2816 & 654 & 490 & 2736 & 2285 & 3390 & 2775 \\
\hline No. visits & 7.25 & 9.30 & 10.95 & 13.00 & 10.24 & 12.33 & 6.98 & 9.32 & 10.07 & 12.05 & 9.47 & 11.57 \\
\hline \multicolumn{13}{|l|}{ Total } \\
\hline No. obs. & 5161 & 3955 & 11865 & 9894 & 17026 & 13849 & 5161 & 3903 & 11865 & 9805 & 17026 & 13708 \\
\hline No. visits & 8.79 & 11.47 & 10.96 & 13.15 & 10.30 & 12.67 & 8.49 & 11.23 & 10.25 & 12.40 & 9.71 & 12.07 \\
\hline
\end{tabular}

†The" 0 excluded" is the case where the observations of " 0 visit" is excluded from our data 
Table 2: Descriptive Statistics

\begin{tabular}{|c|c|c|c|c|c|c|c|c|}
\hline \multirow[b]{2}{*}{ Variable name } & \multicolumn{4}{|c|}{ Pre-reform } & \multicolumn{4}{|c|}{ Post-reform } \\
\hline & Mean & s.d. & $25 \%$ & $75 \%$ & Mean & s.d. & $25 \%$ & $75 \%$ \\
\hline \multicolumn{9}{|l|}{ Explained variables } \\
\hline \multicolumn{9}{|l|}{ Doctor visit } \\
\hline $\operatorname{Head}($ No.of obs. $=5161)$ & 8.79 & 14.22 & 1 & 12 & 8.49 & 14.09 & 1 & 12 \\
\hline Dependant(No.of obs. $=11865)$ & 10.96 & 20.17 & 1 & 13 & 10.25 & 19.49 & 1 & 12 \\
\hline \multicolumn{9}{|c|}{ Individual-specific explanatory variables for dependants(No.of obs.=11865) } \\
\hline Age & 29.28 & 20.19 & 14 & 45 & 30.28 & 20.19 & 15 & 46 \\
\hline Over-69 dummy & 0.04 & 0.19 & 0 & 0 & 0.04 & 0.19 & 0 & 0 \\
\hline Gender dummy $($ male $=1)$ & 0.30 & 0.46 & 0 & 1 & 0.30 & 0.46 & 0 & 1 \\
\hline \multicolumn{9}{|l|}{ Status in household relationship } \\
\hline Spouse dummy & 0.38 & 0.48 & 0 & 1 & 0.38 & 0.48 & 0 & 1 \\
\hline Child dummy & 0.56 & 0.50 & 0 & 1 & 0.56 & 0.50 & 0 & 1 \\
\hline Co-payment rate & 26.94 & 6.80 & 27.75 & 30 & 29.05 & 6.61 & 30 & 31.54 \\
\hline \multicolumn{9}{|c|}{ Household-specific explanatory variables(No.of obs.=5161) } \\
\hline \multicolumn{9}{|l|}{ Household-specific effects } \\
\hline Head's visits & 8.79 & 14.22 & 1 & 12 & 8.49 & 14.09 & 1 & 12 \\
\hline Sum of dependants' visits & 25.20 & 34.56 & 6 & 32 & 23.55 & 32.87 & 5 & 30 \\
\hline Monthly income of head (100,000Yen) & 5.90 & 1.36 & 5.05 & 6.53 & 6.05 & 1.37 & 5.30 & 6.78 \\
\hline Age of head & 47.40 & 7.61 & 43 & 54 & 48.40 & 7.61 & 44 & 55 \\
\hline \multicolumn{9}{|l|}{ Age of dependants } \\
\hline No. of dependants under 9 & 0.30 & 0.62 & 0 & 0 & 0.25 & 0.56 & 0 & 0 \\
\hline No. of dependants $60-69$ & 0.03 & 0.17 & 0 & 0 & 0.03 & 0.17 & 0 & 0 \\
\hline No. of dependants over 69 & 0.12 & 0.35 & 0 & 0 & 0.12 & 0.36 & 0 & 0 \\
\hline Insured-spouse dummy ${ }^{\dagger}$ & 0.87 & 0.34 & 1 & 1 & 0.87 & 0.34 & 1 & 1 \\
\hline No. of children & 1.29 & 1.01 & 0 & 2 & 1.29 & 1.01 & 0 & 2 \\
\hline No. of dependants & 2.30 & 1.07 & 1 & 3 & 2.30 & 1.07 & 1 & 3 \\
\hline No. of dependants visiting doctor & 1.92 & 1.10 & 1 & 3 & 1.90 & 1.09 & 1 & 3 \\
\hline Head's co-payment rate & 9.39 & 1.98 & 10 & 10 & 20.38 & 4.87 & 20.09 & 22.25 \\
\hline
\end{tabular}

${ }^{\dagger}$ This dummy takes one if the spouse in a household is a dependant, otherwise zero.

${ }^{{ }^{\dagger}}$ The s.d. is an abbreviation of standanrd deviation. 
Table 3: Estimates of Head's Model (All-types Households Data)

\begin{tabular}{|c|c|c|c|c|c|c|}
\hline \multirow[b]{2}{*}{ Parameter } & \multicolumn{3}{|c|}{ Pre-reform variables } & \multicolumn{3}{|c|}{ The effect of reform } \\
\hline & Estimate & s.e. & $\mathrm{P}$-value & Estimate & s.e. & $\mathrm{P}$-value \\
\hline & \multicolumn{6}{|c|}{ HURDLE PART } \\
\hline Constant & 0.501 & 0.286 & 0.080 & -0.168 & 0.402 & 0.676 \\
\hline \multicolumn{7}{|l|}{ Household-specifie variables } \\
\hline Age of head & 0.020 & 0.007 & 0.003 & -0.003 & 0.009 & 0.767 \\
\hline \multicolumn{7}{|l|}{ Age of dependants } \\
\hline No. of dependants under 9 & 0.120 & 0.069 & 0.082 & -0.066 & 0.100 & 0.506 \\
\hline No. of dependants $60-69$ & 0.338 & 0.219 & 0.123 & -0.054 & 0.313 & 0.864 \\
\hline No. of dependants over 69 & -0.202 & 0.116 & 0.082 & 0.213 & 0.166 & 0.200 \\
\hline Insured-spouse dummy & 0.000 & 0.105 & 0.999 & 0.045 & 0.148 & 0.760 \\
\hline No. of dependants & -0.231 & 0.054 & 0.000 & -0.019 & 0.076 & 0.799 \\
\hline Monthly income of head $(100,000$ Yen $)$ & -0.061 & 0.034 & 0.070 & 0.050 & 0.047 & 0.289 \\
\hline \multicolumn{7}{|l|}{ Household-specific effects } \\
\hline Sum of dependants' visits & 0.005 & 0.001 & 0.000 & 0.001 & 0.002 & 0.495 \\
\hline No. of dependants visiting doctor & 0.264 & 0.052 & 0.000 & -0.040 & 0.074 & 0.590 \\
\hline \multirow[t]{2}{*}{ Pseudo- $R^{2}$} & 0.105 & & & & & \\
\hline & \multicolumn{6}{|c|}{ POSITIVE-VISITS PART } \\
\hline Constant & 0.988 & 0.186 & 0.000 & -0.331 & 0.258 & 0.200 \\
\hline \multicolumn{7}{|l|}{ Household-specific variables } \\
\hline Age of head & 0.042 & 0.004 & 0.000 & 0.002 & 0.006 & 0.724 \\
\hline \multicolumn{7}{|l|}{ Age of dependants } \\
\hline No. of dependants under 9 & -0.004 & 0.036 & 0.919 & 0.023 & 0.052 & 0.656 \\
\hline No. of dependants $60-69$ & 0.048 & 0.145 & 0.741 & 0.022 & 0.204 & 0.913 \\
\hline No. of dependants over 69 & -0.109 & 0.072 & 0.129 & 0.012 & 0.099 & 0.908 \\
\hline Insured-spouse dummy & -0.067 & 0.062 & 0.281 & -0.089 & 0.086 & 0.302 \\
\hline No. of dependants & -0.125 & 0.037 & 0.001 & 0.009 & 0.052 & 0.858 \\
\hline Monthly income of head $(100,000$ Yen $)$ & -0.033 & 0.020 & 0.093 & -0.013 & 0.027 & 0.635 \\
\hline \multicolumn{7}{|l|}{ Household-specific effects } \\
\hline Sum of dependants' visits & 0.004 & 0.001 & 0.000 & -0.001 & 0.001 & 0.317 \\
\hline No. of dependants visiting doctor & 0.046 & 0.039 & 0.231 & 0.020 & 0.052 & 0.697 \\
\hline Head's co-payment rate & -0.053 & 0.008 & 0.000 & 0.043 & 0.008 & 0.000 \\
\hline \multicolumn{7}{|l|}{ Dispersion parameter } \\
\hline$\alpha$ & 1.874 & 0.060 & 0.000 & & & \\
\hline Pseudo- $R^{2}$ & 0.203 & & & & & \\
\hline
\end{tabular}

${ }^{\dagger}$ The s.e. is an abbreviation of standanrd error. 
Table 4: Estimates of Dependant's Model (All-types Households Data)

\begin{tabular}{|c|c|c|c|c|c|c|}
\hline \multirow[b]{2}{*}{ Parameter } & \multicolumn{3}{|c|}{ Pre-reform variables } & \multicolumn{3}{|c|}{ The effect of reform } \\
\hline & Estimate & s.e. & $\mathrm{P}$-value & Estimate & s.e. & P-value \\
\hline & \multicolumn{6}{|c|}{ HURDLE PART } \\
\hline Constant & 3.343 & 0.556 & 0.000 & -0.715 & 0.807 & 0.376 \\
\hline \multicolumn{7}{|l|}{ Household-specific variables } \\
\hline Age of head & 0.021 & 0.010 & 0.040 & -0.007 & 0.014 & 0.643 \\
\hline \multicolumn{7}{|l|}{ Age of dependants } \\
\hline No. of dependants over 69 & -0.770 & 0.150 & 0.000 & 0.091 & 0.216 & 0.672 \\
\hline No. of children & -0.371 & 0.123 & 0.003 & 0.096 & 0.178 & 0.590 \\
\hline No. of dependants & -2.071 & 0.126 & 0.000 & -0.047 & 0.185 & 0.799 \\
\hline Monthly income of head $(100,000$ Yen $)$ & 0.063 & 0.036 & 0.076 & -0.032 & 0.048 & 0.504 \\
\hline \multicolumn{7}{|l|}{ Household-specific effects } \\
\hline Head's visits & 0.002 & 0.003 & 0.525 & 0.000 & 0.004 & 0.945 \\
\hline No. of dependants visiting doctor & 3.142 & 0.068 & 0.000 & -0.013 & 0.096 & 0.890 \\
\hline \multicolumn{7}{|l|}{ Individual-specific variables } \\
\hline Age & -0.042 & 0.009 & 0.000 & 0.015 & 0.013 & 0.234 \\
\hline Over-69 dummy & 2.451 & 0.438 & 0.000 & -0.074 & 0.638 & 0.907 \\
\hline Gender dummy $($ male $=1)$ & -0.344 & 0.0870 & 0.000 & -0.029 & 0.121 & 0.813 \\
\hline \multicolumn{7}{|l|}{ Status in household relationship } \\
\hline Spouse dummy & -1.443 & 0.383 & 0.000 & 0.527 & 0.568 & 0.354 \\
\hline Child dummy & -1.803 & 0.523 & 0.001 & 0.9544 & 0.766 & 0.213 \\
\hline \multirow[t]{2}{*}{ Pseudo- $R^{2}$} & 0.569 & & & & & \\
\hline & \multicolumn{6}{|c|}{ POSITIVE-VISITS PART } \\
\hline Constant & 5.703 & 0.195 & 0.000 & -0.618 & 0.267 & 0.021 \\
\hline \multicolumn{7}{|l|}{ Household-specific variables } \\
\hline Age of head & 0.005 & 0.003 & 0.117 & 0.003 & 0.005 & 0.522 \\
\hline \multicolumn{7}{|l|}{ Age of dependants } \\
\hline No. of dependants over 69 & -0.087 & 0.054 & 0.107 & -0.069 & 0.075 & 0.356 \\
\hline No. of children & -0.269 & 0.044 & 0.000 & -0.055 & 0.062 & 0.375 \\
\hline No. of dependants & -0.102 & 0.045 & 0.024 & 0.089 & 0.063 & 0.155 \\
\hline Monthly income of head $(100,000$ Yen $)$ & -0.022 & 0.011 & 0.051 & -0.004 & 0.016 & 0.780 \\
\hline \multicolumn{7}{|l|}{ Household-specific effects } \\
\hline Head's visits & 0.007 & 0.001 & 0.000 & -0.000 & 0.001 & 0.944 \\
\hline No. of dependants visiting doctor & 0.263 & 0.022 & 0.000 & -0.066 & 0.029 & 0.021 \\
\hline \multicolumn{7}{|l|}{ Individual-specific variables } \\
\hline Age & -0.019 & 0.003 & 0.000 & 0.001 & 0.004 & 0.790 \\
\hline Over-69 dummy & 0.019 & 0.155 & 0.903 & 0.292 & 0.207 & 0.157 \\
\hline Gender dummy $($ male $=1)$ & 0.076 & 0.032 & 0.019 & 0.021 & 0.045 & 0.645 \\
\hline \multicolumn{7}{|l|}{ Status in household relationship } \\
\hline Spouse dummy & -0.756 & 0.139 & 0.000 & -0.306 & 0.188 & 0.104 \\
\hline Child dummy & -1.407 & 0.193 & 0.000 & -0.414 & 0.271 & 0.127 \\
\hline Co-payment rate & -0.073 & 0.003 & 0.000 & 0.033 & 0.004 & 0.000 \\
\hline \multicolumn{7}{|l|}{ Dispersion parameter } \\
\hline$\alpha$ & 1.372 & 0.023 & 0.000 & & & \\
\hline Pseudo- $R^{2}$ & 0.333 & & & & & \\
\hline
\end{tabular}

${ }^{\dagger}$ The s.e. is an abbreviation of standanrd error. 
Table 5: Estimates of Head's Model (Type-1 Households)

\begin{tabular}{|c|c|c|c|c|c|c|}
\hline \multirow[b]{2}{*}{ Parameter } & \multicolumn{3}{|c|}{ Pre-reform variables } & \multicolumn{3}{|c|}{ The effect of reform } \\
\hline & Estimate & s.e. & $\mathrm{P}$-value & Estimate & s.e. & $\mathrm{P}$-value \\
\hline & \multicolumn{6}{|c|}{ HURDLE PART } \\
\hline Constant & 0.402 & 0.314 & 0.201 & -0.047 & 0.441 & 0.915 \\
\hline \multicolumn{7}{|l|}{ Household-specific variables } \\
\hline Age of head & 0.021 & 0.007 & 0.004 & -0.006 & 0.010 & 0.562 \\
\hline \multicolumn{7}{|l|}{ Age of dependants } \\
\hline No. of dependants under 9 & 0.092 & 0.072 & 0.202 & -0.043 & 0.105 & 0.681 \\
\hline No. of dependants $60-69$ & 0.251 & 0.271 & 0.354 & -0.121 & 0.375 & 0.748 \\
\hline No. of dependants over 69 & -0.233 & 0.138 & 0.090 & 0.279 & 0.198 & 0.159 \\
\hline No. of dependants & -0.240 & 0.057 & 0.000 & -0.005 & 0.080 & 0.953 \\
\hline Monthly income of head $(100,000 \mathrm{Yen})$ & -0.054 & 0.036 & 0.135 & 0.065 & 0.050 & 0.199 \\
\hline \multicolumn{7}{|l|}{ Household-specific effects } \\
\hline Sum of dependants' visits & 0.006 & 0.001 & 0.000 & 0.002 & 0.002 & 0.409 \\
\hline No. of dependants visiting doctor & 0.274 & 0.055 & 0.000 & -0.080 & 0.078 & 0.308 \\
\hline \multirow[t]{2}{*}{ Pseudo- $R^{2}$} & 0.115 & & & & & \\
\hline & \multicolumn{6}{|c|}{ POSITIVE-VISITS PART } \\
\hline Constant & 0.807 & 0.203 & 0.000 & -0.391 & 0.281 & 0.164 \\
\hline \multicolumn{7}{|l|}{ Household-specific variables } \\
\hline Age of head & 0.040 & 0.004 & 0.000 & 0.003 & 0.006 & 0.646 \\
\hline \multicolumn{7}{|l|}{ Age of dependants } \\
\hline No. of dependants under 9 & -0.001 & 0.036 & 0.971 & 0.045 & 0.052 & 0.392 \\
\hline No. of dependants $60-69$ & 0.038 & 0.165 & 0.819 & 0.021 & 0.250 & 0.933 \\
\hline No. of dependants over 69 & -0.119 & 0.088 & 0.181 & -0.042 & 0.123 & 0.735 \\
\hline \multicolumn{7}{|l|}{ No. of children } \\
\hline No. of dependants & -0.122 & 0.038 & 0.001 & 0.020 & 0.053 & 0.704 \\
\hline Monthly income of head $(100,000 \mathrm{Yen})$ & -0.020 & 0.020 & 0.307 & -0.012 & 0.028 & 0.666 \\
\hline \multicolumn{7}{|l|}{ Household-specific effects } \\
\hline Sum of dependants' visits & 0.004 & 0.001 & 0.000 & -0.001 & 0.001 & 0.531 \\
\hline No. of dependants visiting doctor & 0.046 & 0.039 & 0.247 & 0.002 & 0.054 & 0.974 \\
\hline Head's co-payment rate & -0.037 & 0.008 & 0.000 & 0.031 & 0.008 & 0.000 \\
\hline \multicolumn{7}{|l|}{ Dispersion parameter } \\
\hline$\alpha$ & 1.765 & 0.060 & 0.000 & & & \\
\hline Pseudo- $R^{2}$ & 0.273 & & & & & \\
\hline
\end{tabular}

\footnotetext{
${ }^{\dagger}$ The s.e. is an abbreviation of standanrd error.
} 
Table 6: Estimates of Dependant's Model (Type-1 Households)

\begin{tabular}{|c|c|c|c|c|c|c|}
\hline \multirow[b]{2}{*}{ Parameter } & \multicolumn{3}{|c|}{ Pre-reform variables } & \multicolumn{3}{|c|}{ The effect of reform } \\
\hline & Estimate & s.e. & $\mathrm{P}$-value & Estimate & s.e. & $\mathrm{P}$-value \\
\hline & \multicolumn{6}{|c|}{ HURDLE PART } \\
\hline Constant & 6.470 & 0.849 & 0.000 & -2.093 & 1.234 & 0.090 \\
\hline \multicolumn{7}{|l|}{ Household-specific variables } \\
\hline Age of head & 0.025 & 0.011 & 0.026 & -0.012 & 0.015 & 0.431 \\
\hline \multicolumn{7}{|l|}{ Age of dependants } \\
\hline No. of dependants over 69 & 0.326 & 0.270 & 0.228 & -0.342 & 0.406 & 0.400 \\
\hline No. of children & 0.660 & 0.246 & 0.007 & -0.309 & 0.376 & 0.412 \\
\hline No. of dependants & -3.045 & 0.251 & 0.000 & 0.348 & 0.384 & 0.365 \\
\hline Monthly income of head $(100,000$ Yen $)$ & 0.052 & 0.037 & 0.166 & -0.026 & 0.050 & 0.603 \\
\hline \multicolumn{7}{|l|}{ Household-specific effects } \\
\hline Head's visits & 0.003 & 0.003 & 0.427 & -0.001 & 0.004 & 0.782 \\
\hline No. of dependants visiting doctor & 3.035 & 0.069 & 0.000 & -0.010 & 0.098 & 0.922 \\
\hline \multicolumn{7}{|l|}{ Individual-specific variables } \\
\hline Age & -0.046 & 0.010 & 0.000 & 0.021 & 0.014 & 0.124 \\
\hline Over-69 dummy & 0.953 & 0.617 & 0.123 & 0.628 & 0.889 & 0.480 \\
\hline Gender dummy $($ male $=1)$ & -0.387 & 0.094 & 0.000 & -0.027 & 0.130 & 0.835 \\
\hline \multicolumn{7}{|l|}{ Status in household relationship } \\
\hline Spouse dummy & -3.445 & 0.575 & 0.000 & 1.475 & 0.841 & 0.079 \\
\hline Child dummy & -3.864 & 0.692 & 0.000 & 2.066 & 1.006 & 0.040 \\
\hline \multirow[t]{2}{*}{ Pseudo- $R^{2}$} & 0.735 & & & & & \\
\hline & \multicolumn{6}{|c|}{ POSITIVE-VISITS PART } \\
\hline Constant & 5.669 & 0.296 & 0.000 & -0.432 & 0.413 & 0.295 \\
\hline \multicolumn{7}{|l|}{ Household-specific variables } \\
\hline Age of head & 0.007 & 0.003 & 0.030 & 0.004 & 0.005 & 0.354 \\
\hline \multicolumn{7}{|l|}{ Age of dependants } \\
\hline No. of dependants over 69 & 0.038 & 0.100 & 0.701 & -0.032 & 0.141 & 0.819 \\
\hline No. of children & -0.157 & 0.092 & 0.088 & 0.002 & 0.131 & 0.986 \\
\hline No. of dependants & -0.212 & 0.094 & 0.023 & 0.038 & 0.133 & 0.778 \\
\hline Monthly income of head $(100,000$ Yen $)$ & -0.020 & 0.012 & 0.095 & -0.016 & 0.016 & 0.343 \\
\hline \multicolumn{7}{|l|}{ Household-specific effects } \\
\hline Head's visits & 0.007 & 0.001 & 0.000 & 0.001 & 0.001 & 0.712 \\
\hline No. of dependants visiting doctor & 0.260 & 0.022 & 0.000 & -0.070 & 0.030 & 0.022 \\
\hline \multicolumn{7}{|l|}{ Individual-specific variables } \\
\hline Age & -0.019 & 0.003 & 0.000 & 0.001 & 0.004 & 0.856 \\
\hline Over-69 dummy & 0.026 & 0.214 & 0.905 & 0.151 & 0.296 & 0.610 \\
\hline Gender $($ male $=1)$ & 0.081 & 0.035 & 0.021 & 0.007 & 0.048 & 0.886 \\
\hline \multicolumn{7}{|l|}{ Family-relation dummy } \\
\hline Spouse of head & -0.739 & 0.200 & 0.000 & -0.454 & 0.279 & 0.103 \\
\hline Child of head & -1.371 & 0.241 & 0.000 & -0.562 & 0.341 & 0.099 \\
\hline Co-payment rate & -0.073 & 0.003 & 0.000 & 0.034 & 0.004 & 0.000 \\
\hline \multicolumn{7}{|l|}{ Dispersion parameter } \\
\hline$\alpha$ & 1.370 & 0.025 & 0.000 & & & \\
\hline Pseudo- $R^{2}$ & 0.340 & & & & & \\
\hline
\end{tabular}

${ }^{\dagger}$ The s.e. is an abbreviation of standanrd error. 
Table 7: The Results of Tests

\begin{tabular}{c|cccc|ccc}
\hline & \multicolumn{3}{|c|}{ LR test } & \multicolumn{3}{c}{ Z test } \\
\cline { 2 - 8 } & \multicolumn{2}{|c}{ Head } & \multicolumn{2}{c|}{ Dependant } & Head vs. Spouse & Head vs. Child & Head vs. Over-69 \\
\cline { 2 - 8 } Household type & Statistics & d.f. & Statistics & d.f. & Statistics & Statistics & Statistics \\
\hline All types & 27.68 & 21 & 130.66 & 27 & 80.26 & 216.80 & -1.43 \\
& $(0.15)$ & & $(0.00)$ & & $(0.00)$ & $(0.00)$ & $(0.92)$ \\
\hline \multirow{2}{*}{ Type 1 } & 16.74 & 19 & 121.30 & 27 & 129.22 & 155.51 & -26.92 \\
& $(0.61)$ & & $(0.00)$ & & $(0.00)$ & $(0.00)$ & $(1.00)$ \\
\hline
\end{tabular}

† The $\mathrm{P}$ values are shown in parentheses.

${ }^{t \dagger}$ The d.f. is an abbreviation of degrees of freedom. 


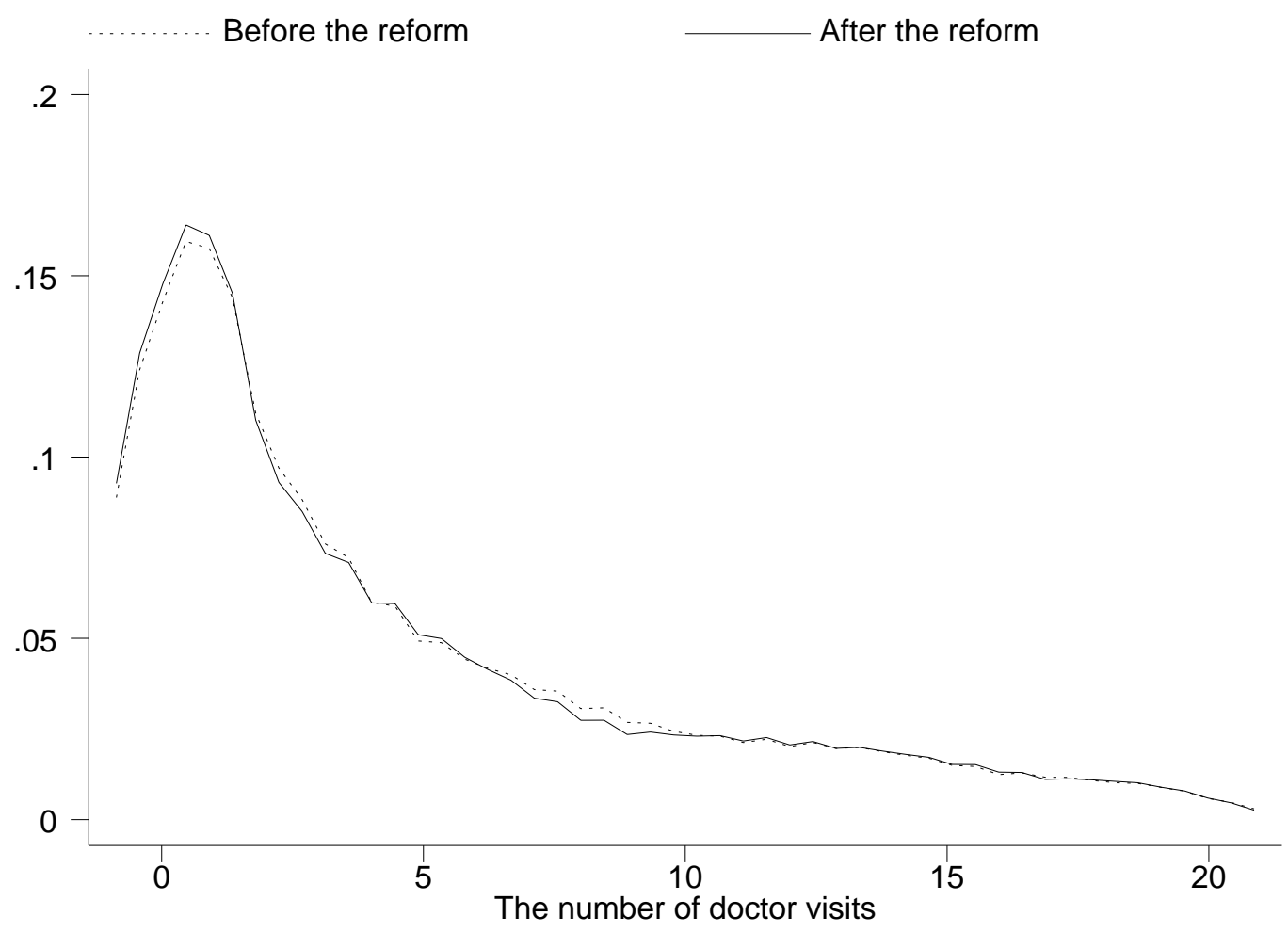

Figure 1. Probability Density of the Number of Doctor Visits (Head) 


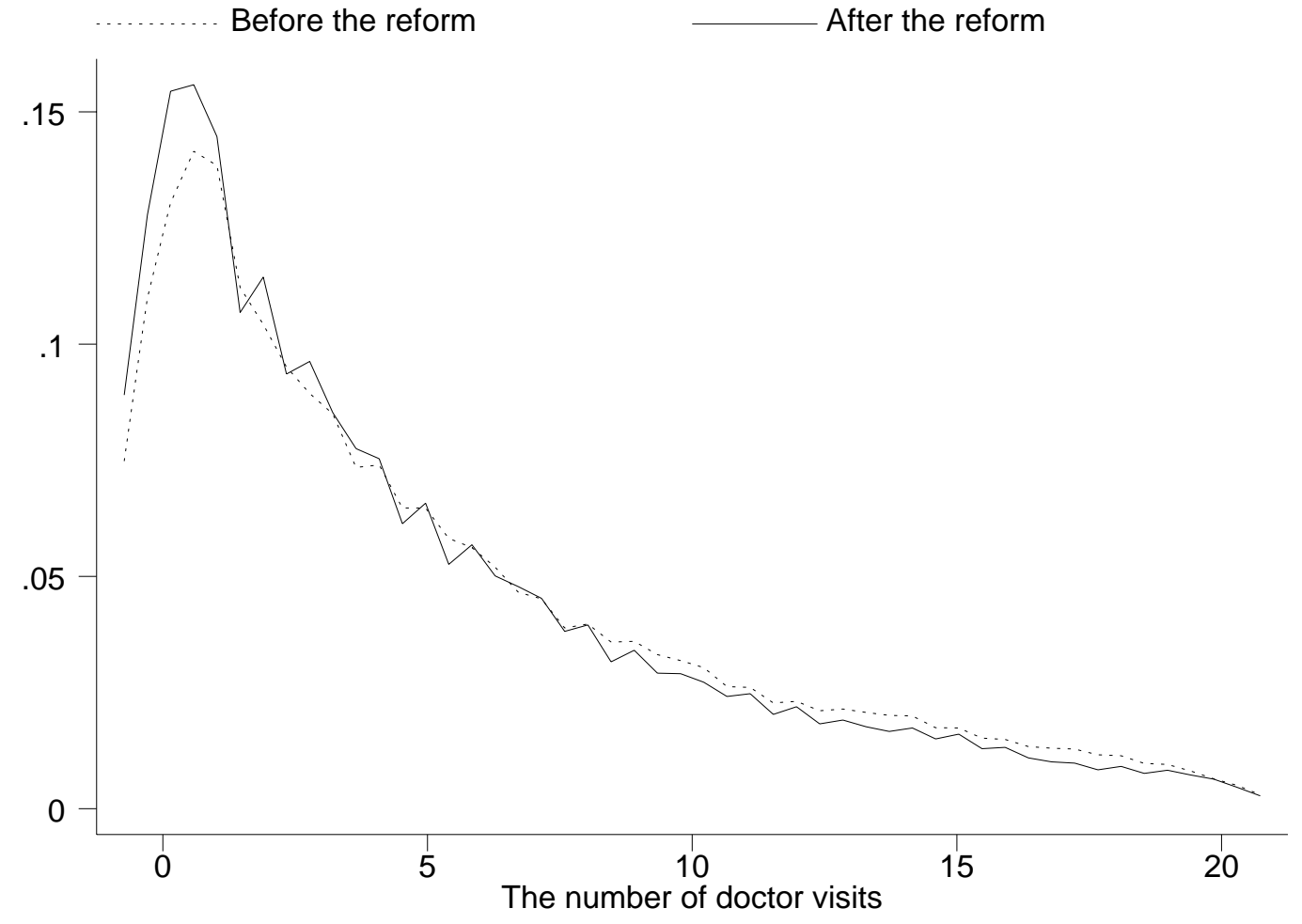

Figure 2. Probability Density of the Number of Doctor Visits (Dependant) 